\title{
Synthesis of hydrophobic fluorinated coating by further addition of isocyanate and amine groups to urethane bond
}

\author{
Pedro Edmundo Martín-Várguez ${ }^{\mathrm{B}}$, Virgilio Ángel González- \\ González ${ }^{A, B}$, Marco Antonio Garza-NavarroA,B, Alejandro Torres- \\ Castro $^{\mathrm{A}, \mathrm{B}}$ \\ Universidad Autónoma de Nuevo León \\ A Facultad de Ingeniería Mecánica y Eléctrica, \\ ${ }^{\text {в } C e n t r o ~ d e ~ I n n o v a c i o ́ n, ~ I n v e s t i g a c i o ́ n ~ y ~ D e s a r r o l l o ~ e n ~ I n g e n i e r i ́ a ~ y ~ T e c n o l o g i ́ a, ~}$
}

\section{RESUMEN}

Se sintetizaron seis precursores fluorinados a partir del polimero comercial Fluorolink E10-H, 3-isocianatopropil etoxisilano y 3-aminopropil metoxisilano. Estos fueron depositados mediante spin-coating sobre sustratos de vidrio, seguido de un recocido a $150^{\circ} \mathrm{C}$ para finalmente obtener los recubrimientos hidrofóbicos. La estructura química fue determinada mediante espectroscopía de infrarojo. La hidrofobicidad fue medida a partir de la medición del ángulo de contacto, cuyos valores se encontraron entre 70 y 93. La hidrofobicidad aumentó con el número de grupos silano hasta un cierto límite antes de perderla. El precursor $P_{111}$ obtuvo las mejores propiedades (estabilidad térmica debajo de $283.5{ }^{\circ} \mathrm{C} y$ ángulo de contacto de $93^{\circ}$ ) de este trabajo.

\section{PALABRAS CLAVE}

Síntesis, fluronados, spin-coating, uretano.

\section{ABSTRACT}

Six fluorinated precursors were synthesized from commercial polymer Fluorolink E10-H, 3-isocyanatepropyl ethoxysilane and 3-aminepropyl methoxysilane. The precursors were spin-coated on glass substrates and annealed at $150^{\circ} \mathrm{C}$ for $2 \mathrm{~h}$ to obtain hydrophobic coatings. Chemical structure of was determined by infrared spectroscopy. Hydrophobicity was measured from drop contact angle, ranging between 70 and $93^{\circ}$. Hydrophobicity increased with the number of silane groups until a certain limit before losing it. Precursor $P_{111}$ has the better properties (thermal stability $283.5^{\circ} \mathrm{C}$, contact angle 93\%) within our work.

\section{KEYWORDS}

Synthesis, fluorinated, spin-coating, urethane. 


\section{INTRODUCTION}

Coatings are used to modify the inherent properties of a surface acting as a physical barrier against their environment. In recent years, interesting applications have appeared for hydrophobic coatings in self-cleaning glasses, which are mainly composed of a hydrophobic layer able to roll off water, for example in solar panels, green houses, photovoltaic devices, heat transfer surfaces for conditioning air, resistant corrosion coatings. ${ }^{1-4}$ Also, they could act as a matrix of other components which could give additional characteristics, going further than just for hydrophobic coating, such as in coating against microbial attack, ${ }^{5}$ in self-cleaning cloths ${ }^{6}$ or in proton exchange membrane cells. ${ }^{7}$ By definition, a hydrophobic coating must have a contact angle above of $90^{\circ}$. Hydrophobicity rely on wettabilty of the surface, ${ }^{8}$ depending mainly on the interactions of the liquid with the solid surface and another surrounding fluid, usually the air. Its nature is divided into two components: a physical part, related on the topology of surface (roughness), and chemical part, related to the energy necessary to form a new surface between the liquid-solid interface (surface energy).

The molecules used in hydrophobic applications are composed of two parts: an organic side being hydrophobic, such as alkanes chains, ${ }^{9}$ and an inorganic side having a siloxane/silane chain which could be attached to the glass. ${ }^{10}$ To enhance the hydrophobicity of the organic side, it should have a low surface energy to minimize close range interactions, letting Lifshitz-van der Waals interactions to act; ${ }^{11,12}$ specially whether it possess a high polarizability. ${ }^{13}$ For this reason, fluoridated materials were first developed because of the high electronegativity of fluorine atom, which difficults the polarization of the molecule, resulting in a low intermolecular force and thus, a low surface energy. Moreover, C-F bond has a good thermal and chemical stability. ${ }^{14,15}$ Although nowadays flourinated compounds are being avoided, they are still a good option whether there is the appropriate care of their wastes.

The organic and inorganic sides of the hydrophobic molecule are attached together by a chemically and thermally stable bond, such as the urethane bond. Even though the actual trend is to find alternative synthetic routes to avoid toxic isocyanates in concordance with green chemistry, ${ }^{16,17}$ urethane bond offers possibility of further functionalization, which can be exploited to synthesize other carbamate derivates incorporating additional silane groups, which could improve hydrophobicity by forcing the fluorinate side to be outwards. ${ }^{17}$ Urethane bond reacts with hydroxyles, carboxylic acids, anhydrides, epoxydes or even with other isocyanates, but it shows more affinity with amines. ${ }^{18-20}$ There are several studies probing this assumption; for example, anhydrides, ${ }^{21}$ epoxydes, ${ }^{17}$ have been introduced to the same molecule and contact angles above of $105^{\circ}$ were obtained.

In this work, we report the synthesis of derivative carbamates from urethane bond by addition of functionalized amine and isocyanate silane groups in order to improve the hydrophobic properties of a commercial fluorinated polymer. In this way, reactivity of isocyanate group may be exploited, mainly because isocyanate can still react with urethane bond to form more complex carbamates. 


\section{METHODOLOGY}

\section{Reactants}

Fluorolink ${ }^{\circledR}$ E-10 H $\left(\mathrm{F}_{\mathrm{OH}}\right)$, purchased from Solvay Solexis, is a commercial fluoridated polymer difunctionalized with alcohol with $57 \% \mathrm{~F}$ and a molecular mass of 1700 uma. 3-isocyanate propyl triethoxysilane (IPTES) and 3-amine propyl trimethoxysilane (APTMS) were used as silanes. As catalyst, a mixture of hexamethylenetetramine (HTMA) and $\mathrm{CuCl}_{2} \cdot 2 \mathrm{H}_{2} \mathrm{O}$ in a stoichiometric ratio $1: 2$ were used. Chloroform, tetrahydrofurane were used as solvents, and $\mathrm{HCl}(37 \%$ purity), $\mathrm{HNO}_{3}$ (69.4\% purity) and $\mathrm{NaOH}$ (97\% purity) for the washing process. All reactants were purchased from Sigma-Aldrich $\AA$.

\section{Synthesis of hydrophobic precursors}

In a $125 \mathrm{~mL}$ balloon flask stirred with magnetic agitation, $10 \mathrm{~mL}$ of chloroform as solvent and $30 \mathrm{mg}$ of a mixture of HTMA:Cu as catalyst were added; $4.7 \mathrm{mmol}$ of FOH and the stoichiometric quantities of IPTES and/or APTMS and reaction times as signaled in table 1 were used to synthesize hydrophobic precursors. For products $\mathrm{P}_{111}$ and $\mathrm{P}_{112}, \mathrm{P}_{11}$ product was first formed and then 9.4 and $18.8 \mathrm{mmol}$ respectively of APTMS were added. Likewise, the products $\mathrm{P}_{121}$ and $\mathrm{P}_{12}$ were first formed and then $9.4 \mathrm{mmol}$ of APTMS were added. Reaction temperature was set at $80^{\circ} \mathrm{C}$ in all cases. The products were kept in $5 \mathrm{~mL}$ of chloroform until use to avoid their reaction with environmental air. Excess of solved was removed in a rotary evaporator.

Table I. Stoichiometric ratios of reactants used for the fabrication of fluorinaded precursors.

\begin{tabular}{|c|c|c|c|c|}
\hline Product & $\mathrm{F}(\mathrm{mmol})$ & $\mathrm{I}(\mathrm{mmol})$ & $\mathrm{A}(\mathrm{mmol})$ & Time $(\mathrm{min})$ \\
\hline $\mathrm{P}_{11}$ & 4.7 & 9.4 & - & 60 \\
\hline $\mathrm{P}_{12}$ & 4.7 & 18.8 & - & 135 \\
\hline $\mathrm{P}_{13}$ & 4.7 & 28.2 & - & 130 \\
\hline $\mathrm{P}_{111}$ & 4.7 & 9.4 & 9.4 & 80 \\
\hline $\mathrm{P}_{112}$ & 4.7 & 9.4 & 18.8 & 80 \\
\hline $\mathrm{P}_{121}$ & 4.7 & 18.8 & 9.4 & 80 \\
\hline
\end{tabular}

\section{Coating synthesis}

Corning-glass of $2.5 \times 2.5 \mathrm{~cm}$ were used as substrates. They were washed with soap and water to remove any dust on their surface. After, they were sonicated 30 min, first in a $\mathrm{CH}_{3} \mathrm{OH} / \mathrm{HCl}$ 1:1 solution and then in concentrated $\mathrm{H}_{2} \mathrm{SO}_{4}$, rinsing with distillate water between each step, according to the methodology reported by Cras et al. ${ }^{6}$ Substrates were kept in the washing generated distillate water at $\mathrm{pH}$ 1-2 prior use. To deposit the coatings on glass, a mother solution was made from $250 \mathrm{mg}$ of each precursor redisolved in $4 \mathrm{~mL}$ of chloroform, forming seven solutions of $62.5,31.3,7.81,3.91,0.978,0.488$ and $0.122 \mathrm{~g} \cdot \mathrm{mL}^{-1}$. Then, for each product $200 \mu \mathrm{L}$ of each concentration were spin coated in cycles of 1000 $\mathrm{rpm}$ for $10 \mathrm{~s}$ followed of $2500 \mathrm{rpm}$ for $40 \mathrm{~s}$. Coatings were annealed at $150{ }^{\circ} \mathrm{C}$ for $2 \mathrm{~h}$ in a convection oven. Coatings were made by triplicate. 


\section{Characterization}

IR spectra were recorded in a Thermo Scientific Nicolet 6700 by pipetting a small drop of precursors on $\mathrm{KBr}$ pellets. Thermal stability was measured in a thermogravimetric analysis equip Shimadzu A-50, from room temperature to $500{ }^{\circ} \mathrm{C}$ at a rate of $10{ }^{\circ} \mathrm{C} \cdot \mathrm{min}^{-1}$. Thickness of selected coatings were measured in a FEG scanning electron microscope FEI Novananosem 200; substrates' conductivity was increased with a thin gold film in an $\mathrm{Au} /$ graphite evaporator Quorum Q150R-ES to facilitate their SEM analysis. Contact angle measurements were made with $20 \mu \mathrm{L}$ of distillate water from three photos on three different spots on the surface of glass to have a mean value.

\section{RESULTS AND DISCUSSIONS}

The reactions were monitored as IR signal at $1720 \mathrm{~cm}^{-1}$, corresponding to asymmetric stretching of carbonyl of urethane, present in all products, appears despite of signal at $2270 \mathrm{~cm}^{-1}$, related to out plane stretching of isocyanate group. IR spectra of FOH, IPTES and APTMS are observed in figure 1 and their respective assignations are shown in table II. In figure 2, their color solutions in chloroform are observed.

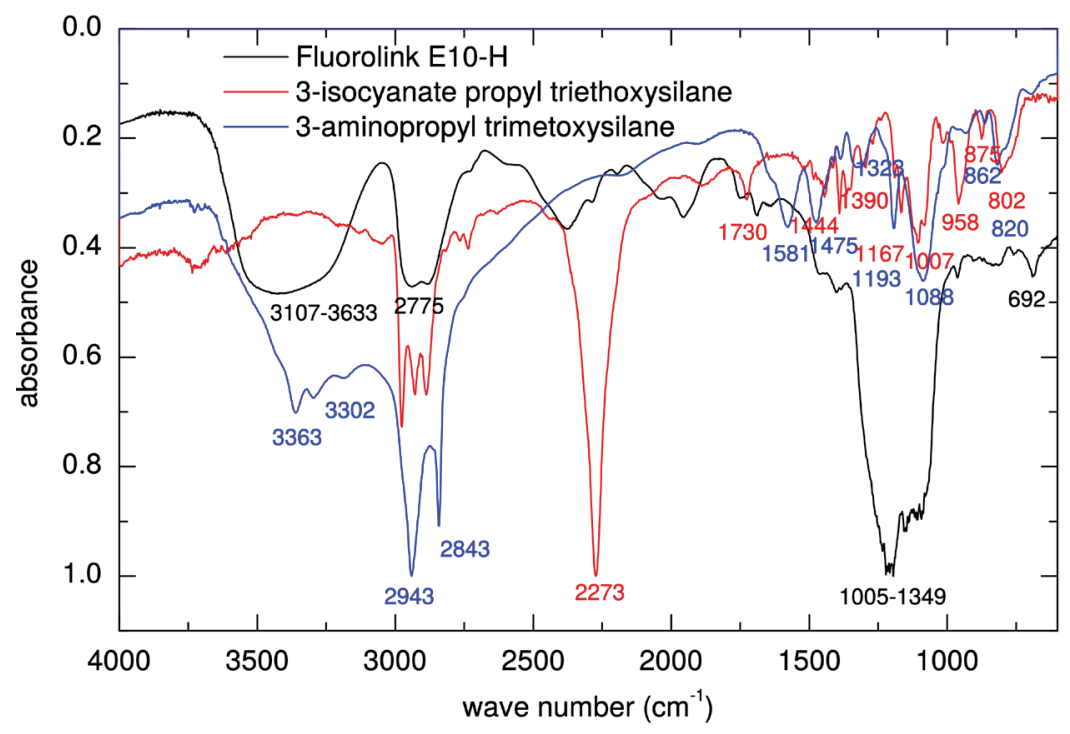

Fig. 1. IR spectra of reactants employed.
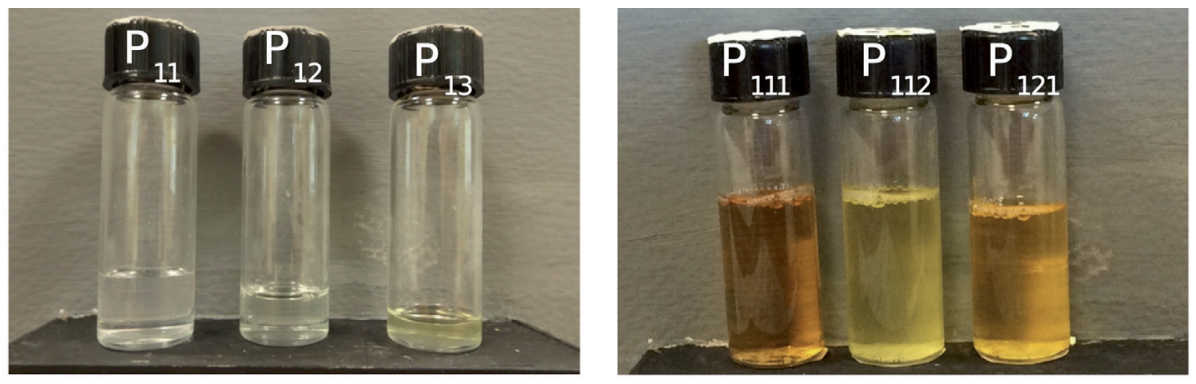

Fig. 2. Acetonitrile solutions of synthesized products. 
Table II. Signal assignations of IR spectra of reactants.

\begin{tabular}{|c|c|c|}
\hline Reactant & Observed signal $\left(\mathrm{cm}^{-1}\right)$ & Assignation \\
\hline \multirow[t]{6}{*}{ IPTES } & 802,1107 & $\mathrm{~V}_{\mathrm{s}} \mathrm{Si}-\mathrm{O}-\mathrm{CH}_{2} \mathrm{CH}_{3}$ \\
\hline & 875 & v Si-C \\
\hline & 952 & v out plane $\mathrm{C}-\mathrm{O}-\mathrm{C}$ \\
\hline & 1167 & Vas $\mathrm{Si}-\mathrm{O}-\mathrm{CH}_{2} \mathrm{CH}_{3}$ \\
\hline & 2273 & v out face $N C N$ \\
\hline & $2888-2978$ & $\mathrm{v}_{\mathrm{s}}-\mathrm{CH}_{3}$ \\
\hline \multirow[t]{9}{*}{ APTMS } & $820-1088$ & vs $\mathrm{Si}-\mathrm{O}-\mathrm{CH}_{3}$ \\
\hline & 862 & v Si-C \\
\hline & 1193 & $\mathrm{~V}_{\text {as }} \mathrm{Si}-\mathrm{O}-\mathrm{CH}_{3}$ \\
\hline & 1323 & v C-N \\
\hline & 1475 & $\delta-\mathrm{NH}_{2}$ \\
\hline & 1581 & $\delta-\mathrm{NH} 2$ \\
\hline & 2843 & $v_{s} C-H$ \\
\hline & 2943 & $\mathrm{v}_{\mathrm{s}} \mathrm{C}-\mathrm{H}$ \\
\hline & 3302,3363 & $\mathrm{v}_{\mathrm{s}}-\mathrm{NH}_{2}$ \\
\hline \multirow[t]{4}{*}{$\mathrm{FOH}$} & 692 & $\mathrm{CF}_{2}$ \\
\hline & $1005-1349$ & $v \mathrm{C}-\mathrm{F}, \mathrm{C}-\mathrm{O}-\mathrm{C}$ \\
\hline & $2775-3018$ & $\mathrm{v} \mathrm{CH}$ \\
\hline & $3107-3633$ & $\mathrm{v}_{\mathrm{s}} \mathrm{OH}$ \\
\hline
\end{tabular}

In order to find the minimal quantity of the mixture of HTMA:Cu as catalyst, $\mathrm{P}_{12}$ was chosen because the product $\mathrm{P}_{11}$ was already easily synthesized by other methods reported in literature, for example with dibutyltin dilaurate (DBTL). ${ }^{17,22}$ For $\mathrm{P}_{12}$, reaction time as a function of HTMA:Cu added is shown in figure 3. After $0.7 \% \mathrm{~m} / \mathrm{m}$ of catalyst added there is no significant difference between reaction time and catalyst quantity added. Individual optimization for other products was not done because; thus, for all products $30 \mathrm{mg}$ of HTMA:Cu mixture as catalyst were stated for each $4 \mathrm{~g}$ of $\mathrm{FOH}$ used in reaction.

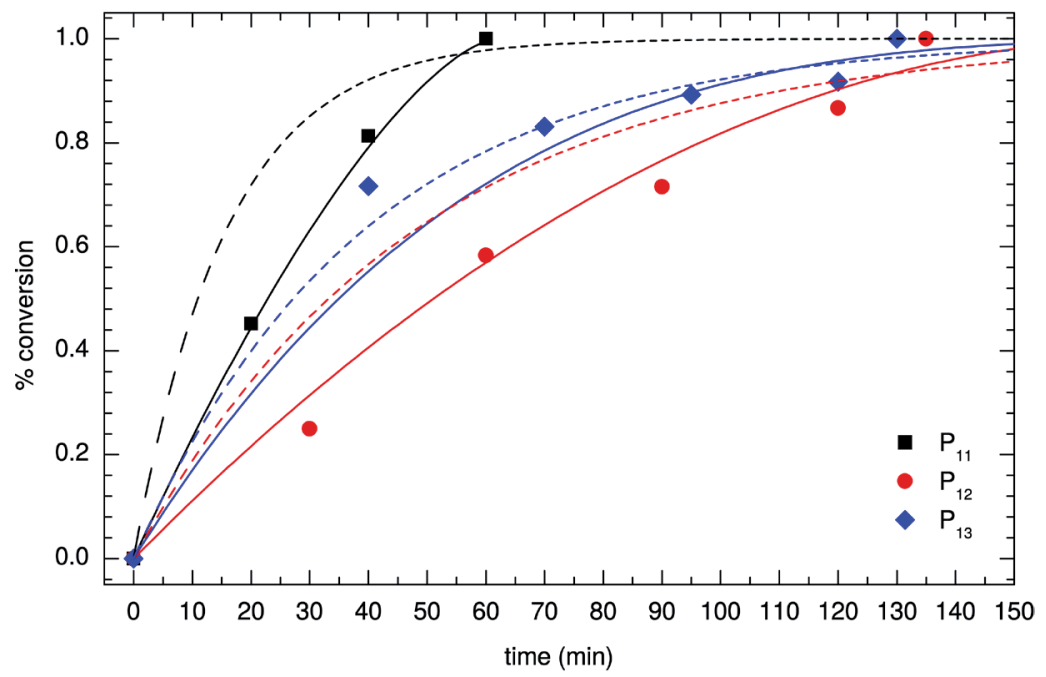

Fig. 3. Kinetics reaction of $P_{12}$. 
IR spectra of products $\mathrm{P}_{11}, \mathrm{P}_{12}$ and $\mathrm{P}_{13}$ synthesized are shown in figure 4. All spectra are normalized to asymmetrical stretching of C-O-C at $958.5 \mathrm{~cm}^{-1}$ from ether bonds of polymer, which should be present in all products. Urethane bond in product $\mathrm{P}_{11}$ is clearly formed as suggested by signals of the scissoring of $-\mathrm{NH}$ at $3348 \mathrm{~cm}^{-1}$ and the asymmetrical stretching of carbonyl at $1722 \mathrm{~cm}^{-1}$, which are characteristics of urethane bond. ${ }^{23-25}$ IR spectra of products $\mathrm{P}_{12}$ and $\mathrm{P}_{13}$ are very similar compared with product $\mathrm{P}_{11}$, which means that they have a similar chemical structure. Signal at $3348 \mathrm{~cm}^{-1}$ increase almost linearly as number of siloxanes are increased too, which is related to number of $-\mathrm{NH}$ present in the polymeric chain. Signal at $1644 \mathrm{~cm}^{-1}$ is due to intermolecular interaction of $\mathrm{H}$ and $\mathrm{O}$ of carbonyl, ${ }^{26}$ whose presence is already in product $\mathrm{P}_{11}$ but its intensity grows up in $\mathrm{P}_{12}$ and $\mathrm{P}_{13}$. We believe that intensity at this wavenumber augments because the interatomic distance between $\mathrm{O}$ and $\mathrm{H}$ is reduced as much as more silane groups are in each side of molecule, increasing steric impediment causing that $\mathrm{H}$ was displaced to $\mathrm{O}$. Assignation of main signals of products $\mathrm{P}_{11}, \mathrm{P}_{12}$ and $\mathrm{P}_{13}$ are shown in table III.

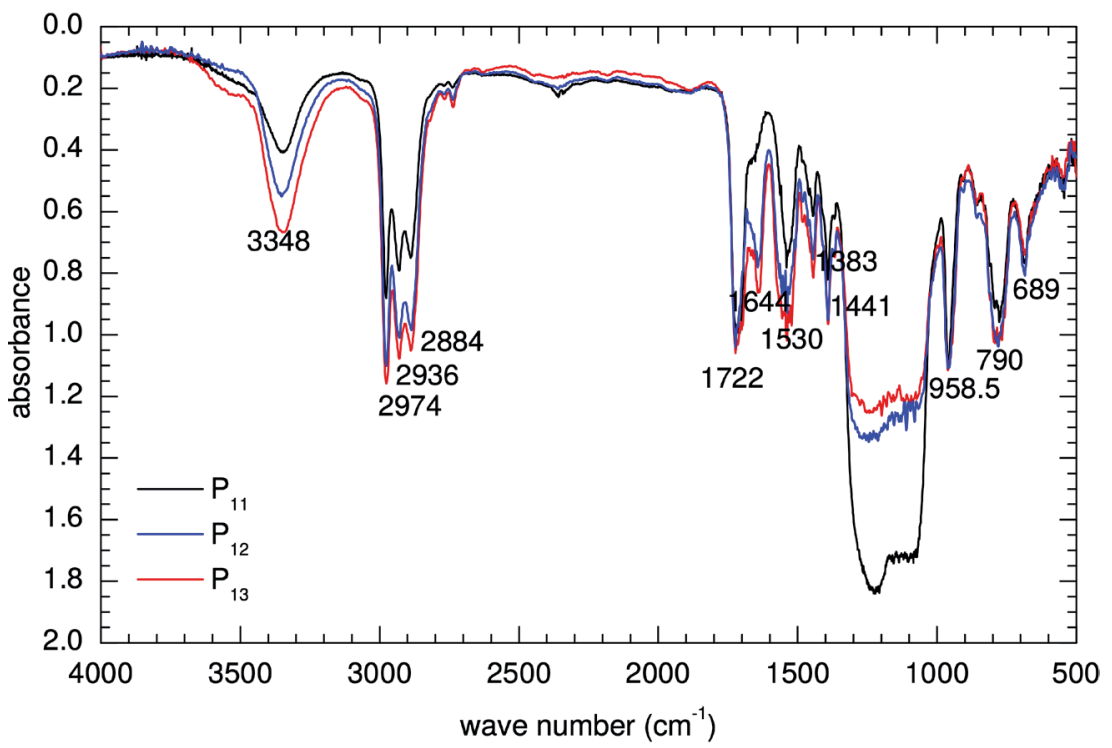

Fig. 4. IR spectra of products $\mathrm{P}_{11}, \mathrm{P}_{12}$ and $\mathrm{P}_{13}$.

Table III. IR Signal assignations of products $\mathrm{P}_{11}, \mathrm{P}_{12}$ and $\mathrm{P}_{13}$.

\begin{tabular}{|l|l|}
\hline Signal $\left(\mathrm{cm}^{-1}\right)$ & Assignation \\
\hline 3348 & $\delta-\mathrm{NH}$ \\
\hline $2974,2936,2884$ & as $-\mathrm{CH}$ \\
\hline 1722 & $\mathrm{~V}_{\text {as }}-\mathrm{C}=\mathrm{O}$ \\
\hline 1644 & $\mathrm{H}$ coupling \\
\hline 1530 & Vas $-\mathrm{NH}$ (urethane) \\
\hline 1441 & Stretching $-\mathrm{CH}_{2},-\mathrm{CH}_{3}$ \\
\hline 1383 & Stretching $-\mathrm{CH}_{3}$ \\
\hline 1200 & Fluorine \\
\hline 958.5 & Vas $\mathrm{C}-\mathrm{O}-\mathrm{C}$ \\
\hline
\end{tabular}


In figure 5 IR spectra of products $\mathrm{P}_{111}, \mathrm{P}_{112}$ and $\mathrm{P}_{121}$ are shown, as well as their signal assignations in table IV. Around $2834-2968 \mathrm{~cm}^{-1}$, in region corresponding to alkyl, signal has become a quartet due to the inclusion of $-\mathrm{CH}_{3}$ from APTMS instead of a $-\mathrm{CH}_{2} \mathrm{CH}_{3}$ into the chain. Although it can be though that all product are the same as in the another products because their signals are very close to them, there are some differences like there is also a shoulder around $3500 \mathrm{~cm}^{-1}$ in signals of amines, and a shift of $5 \mathrm{~cm}^{-1}$ of asymmetrical stretching of $-\mathrm{C}=\mathrm{O}$ and a left stretching of asymmetrical stretching of $-\mathrm{NH}$ which let us conclude that we have synthesized new derivatives. During synthesis, for products $\mathrm{P}_{111}, \mathrm{P}_{112}$ and $\mathrm{P}_{121}$ a characteristic blue copper-ammonium-like coloration has appeared, which disappears as reaction reaches the end until the orange-like coloration observed in figure 2. This shift to longer wavelengths can suggest an electron delocalization due to the presence of more conjugated bonds into the structures.

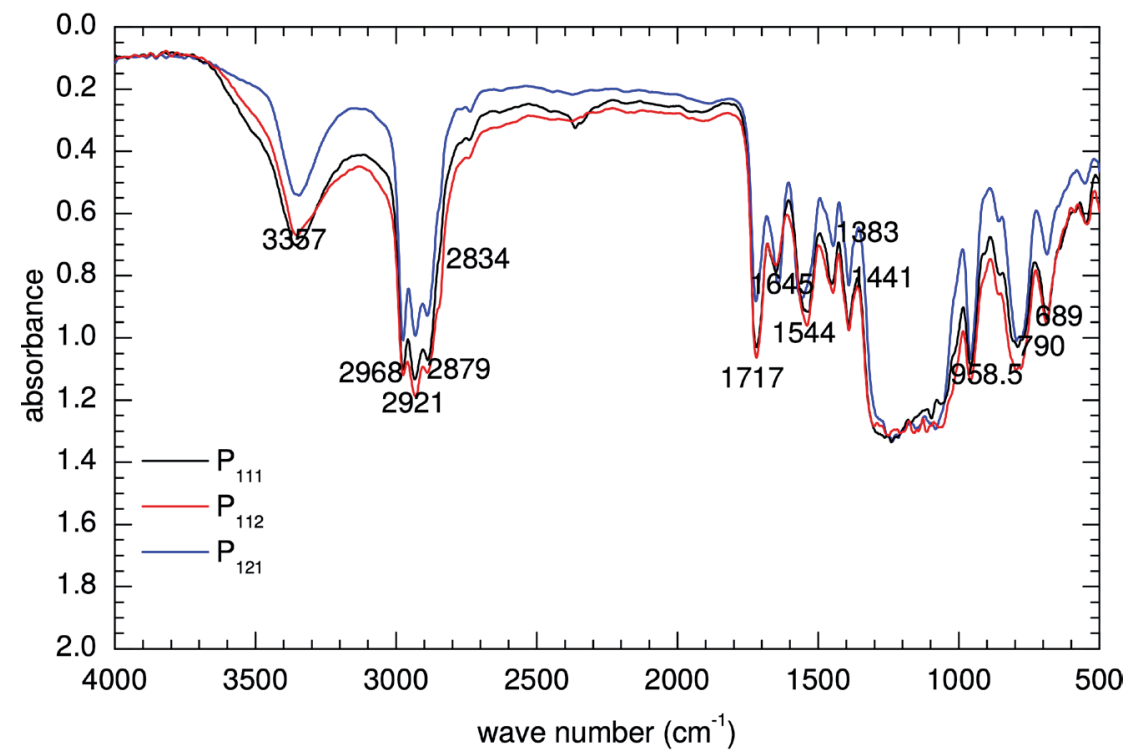

Fig. 5. IR spectra of products $\mathrm{P}_{111}, \mathrm{P}_{112}$ and $\mathrm{P}_{121}$.

Table IV. Signal assignations of products $\mathrm{P}_{111}, \mathrm{P}_{112}$ and $\mathrm{P}_{121}$.

\begin{tabular}{|l|l|}
\hline Signal $\left(\mathrm{cm}^{-1}\right)$ & Assignation \\
\hline 3357 & $\delta-\mathrm{NH}$ \\
\hline $2968,2921,2879,2834$ & $\mathrm{~V}_{\text {as }}-\mathrm{CH}$ \\
\hline 1717 & $\mathrm{~V}_{\text {as }}-\mathrm{C}=\mathrm{O}$ \\
\hline 1645 & $\mathrm{H}$ coupling \\
\hline 1544 & Vas $-\mathrm{NH}$ (urethane) \\
\hline 1441 & stretching $-\mathrm{CH}_{2},-\mathrm{CH}_{3}$ \\
\hline 1383 & stretching $-\mathrm{CH}_{3}$ \\
\hline 1200 & flourine \\
\hline 958.5 & Vas $\mathrm{C}-\mathrm{O}-\mathrm{C}$ \\
\hline
\end{tabular}


The contact angle as a function of concentration of each polymer is represented in figure 6. Although the macroscopic shape that the drop can acquire depends on frontier conditions of the physical model describing the behavior of the liquid-vapor interface, there are several mathematical simplifications which help to calculate the contact angle. One simple way is to suppose that the drop contour is described by the equation of a circumference. This assumption can be done whether Bond number is less than $1 .{ }^{27}$ Therefore, surface tension is more important than gravity component. For water, this is reached whether drop volume is less than $85 \mu \mathrm{L},{ }^{27}$ although ASTM D7334-08 norm recommend use less than $20 \mu \mathrm{L}$.

As sketched in figure 6 , the drop contour was calculated by mean radius $\mathrm{R}_{\mathrm{m}}$ and high $\mathrm{hz}^{28}$ by,

$$
h(r)=-R_{m} / \tan \theta \pm\left(R_{m}^{2} / \sin ^{2} \theta-r^{2}\right)^{1 / 2}
$$

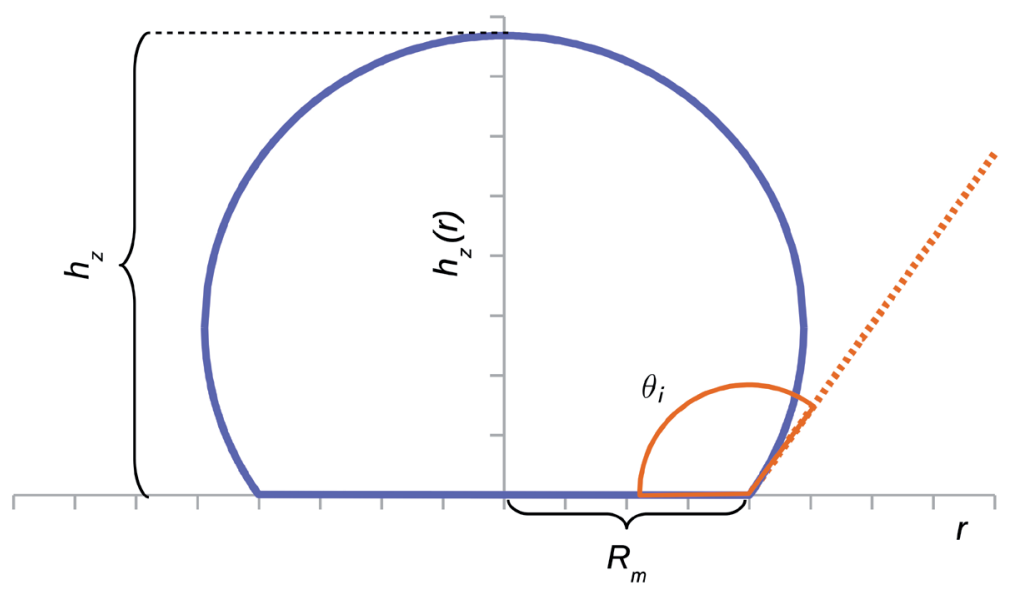

Fig. 6. Contour of a drop approximated as a circle.

There are further approaches which take in count many another factors, but they were neglected in this work. ${ }^{29-32}$ Thus, contact angle was approximated measuring high $\mathrm{h}_{\mathrm{z}}$ and width $\mathrm{R}_{\mathrm{m}}$ of the drop, supposing that drop's contour behaves like a circle pathway as in figure 6 , thus contact angle $\theta$ is found by solving equation 2 at the point $(\mathrm{r}, \mathrm{h})=\left(0, \mathrm{~h}_{\mathrm{z}}\right)$,

$$
\left(h_{z} / R_{m}\right) \sin \theta+\cos \theta+1=0
$$

Traditionally, hydrophobic coatings are added by sol-gel between silanes and silicates on glass; but in this work we attempted to do it in a faster way, for this reason the only treatment allowing their adherence on glass is the acid wash prior coating. It is expected that as more silane groups are added into the molecule, higher is the contact angle because it is easier to be attached to glass, ${ }^{17}$ as observed in figure 7. This phenomenon is observed clearly in products $P_{11}$, $\mathrm{P}_{12}$ and $\mathrm{P}_{13}$ where they exhibit a higher contact angle as polymer concentration increases, whose addition can go further the monolayer. However, increasing silane number has also its limitations, specially whether these groups are close 
into the same molecule. This result in a steric impediment diminishing this phenomenon because there is a disorder in the arrangement of the molecules on the substrate, letting some hydrophilic sides of the molecule be outside to air, decreasing hydrophobicity.

It is interesting to notice that in products $\mathrm{P}_{111}, \mathrm{P}_{112}$ and $\mathrm{P}_{121}$ at low concentrations the higher contact angles are obtained. This could be related to silane groups which are so close within the molecule, thus, once the monolayer is formed further addition is not easily attached to the surface, due to the diminishing of free "spaces" on it. Even, when more material is added in excess this results in a chaotic coating because many molecules achieve to fill in all the space on glass surface, and therefore there are hydrophilic sides which are outside, reducing hydrophobicity. In fact, at high concentrations, a visually poor-quality coatings were observed.

In figure 8 , thermograms of synthesized products are plotted as well as thermal decomposition temperatures are reported in table $\mathrm{V}$. In this figure is also plotted product $P_{11 w c}$, which is like product $P_{11}$ catalyzed just with temperature at $125^{\circ} \mathrm{C}$ for $3 \mathrm{~h}$. Thermal stability of all products ranges $260-270^{\circ} \mathrm{C}$, except for product $\mathrm{P}_{11}$ which is lower and product $\mathrm{P}_{111}$ which is higher. This is a consequence of the bonding strength within the molecules. Several silane-based functionalized polymers are reported which decompose around $300-380{ }^{\circ} \mathrm{C},{ }^{3,33}$ and full fluorine-functionalized polymers around $340-390{ }^{\circ} \mathrm{C} .{ }^{34,35}$ Considering that urethanes usually decomposes around $180-200^{\circ} \mathrm{C}^{36}$ and we have worked with low fluorine polymers (57\%), the results are sufficiently satisfactory, specially for product $\mathrm{P}_{111}$.

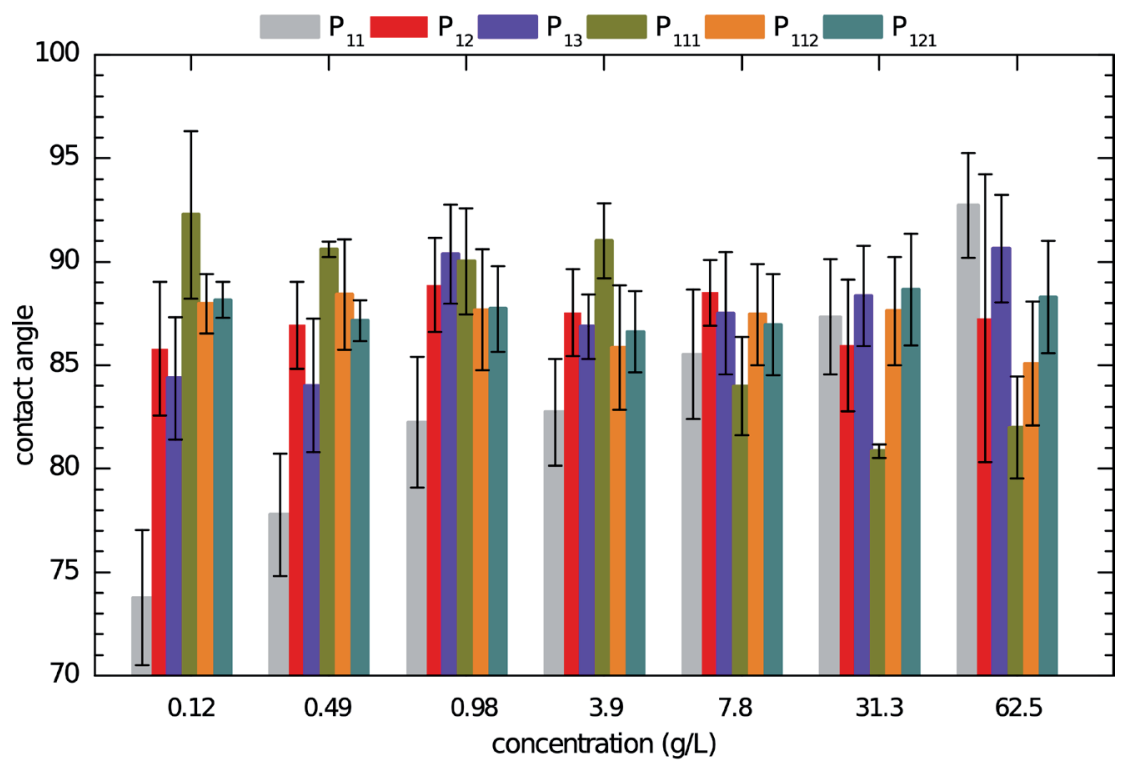

Fig. 7. Contact angles of coatings at several concentrations. 


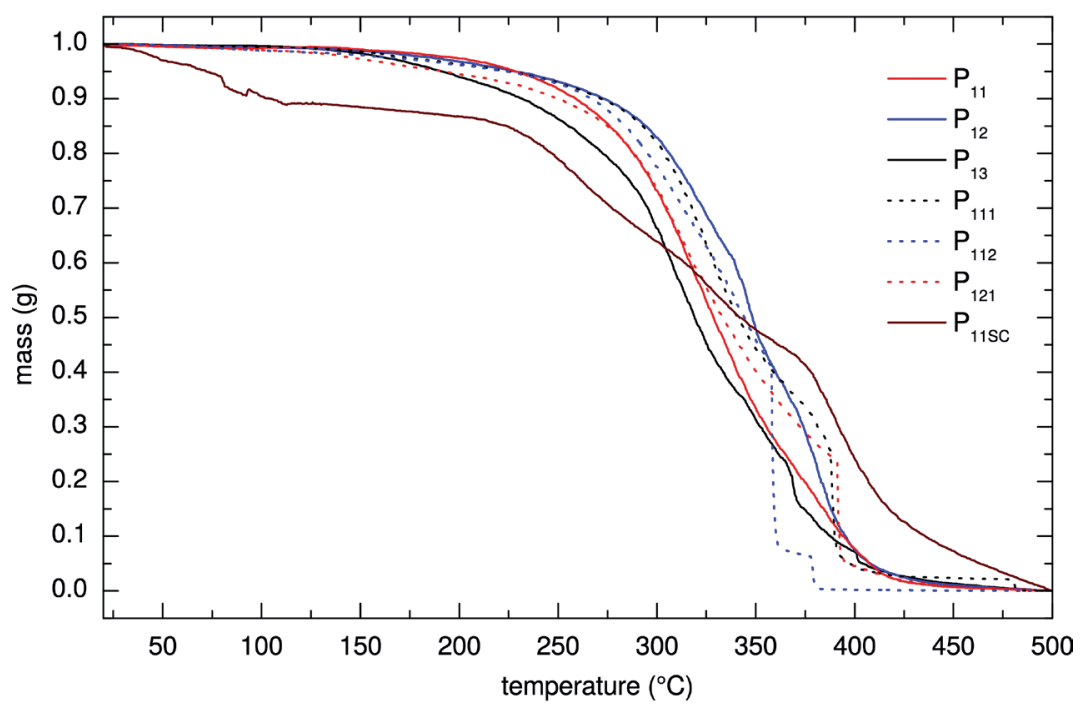

Fig. 8. Thermograms of synthesized products.

Low thermal stability of product $\mathrm{P}_{11 \mathrm{wc}}$ is explained due to the high synthesis temperature used compared with other ones, where less stable and volatile subproduct should be formed. This product undergo decomposition in whole range of analysis. Temperature accelerates reaction rate in urethanes, but it also accelerates other side reactions or even equilibrium can be displaced to reactants. ${ }^{19,22,37}$ Coloration of product $\mathrm{P}_{11 \mathrm{wC}}$ is darker than $\mathrm{P}_{11}$, which are an indicative that their composition is different.

Table V. Thermal stability temperatures of the synthesized products.

\begin{tabular}{|c|c|c|c|c|c|c|c|}
\hline Product & $\mathrm{P}_{11}$ & $\mathrm{P}_{12}$ & $\mathrm{P}_{13}$ & $\mathrm{P}_{111}$ & $\mathrm{P}_{112}$ & $\mathrm{P}_{121}$ & $\mathrm{P}_{11 \mathrm{WC}}$ \\
\hline $\mathrm{T}\left({ }^{\circ} \mathrm{C}\right)$ & 268.93 & 277.70 & 261.40 & 283.50 & 268.18 & 271.43 & 228.06 \\
\hline
\end{tabular}

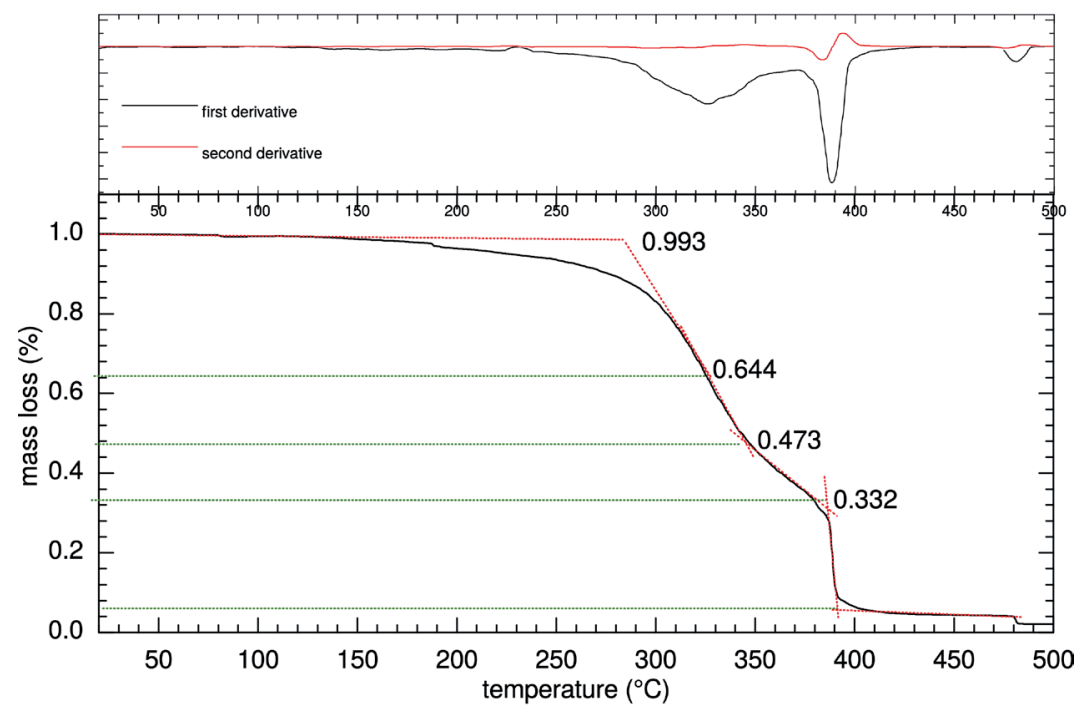

Fig. 9. Thermogram of product $P_{111}$. 
When molecule increases its kinetic energy by effect of temperature, its motion is more restricted whether there is a steric impediment, making unstable bonds which are around them..$^{38}$ Based on this, chemical structures of products $\mathrm{P}_{12}, \mathrm{P}_{13}$, $\mathrm{P}_{111}, \mathrm{P}_{112}$ and $\mathrm{P}_{121}$ should be structurally similar in some way to product $\mathrm{P}_{11}$ due that there is not a temperature difference greater than $10^{\circ} \mathrm{C}$.

Given the thermal stability and contact angle, of synthesized products, $\mathrm{P}_{111}$ has the promising hydrophobic characteristics. In figure 9 is observed a more detailed plot. Five mass loss are observed. Considering also the other products, as molecule has more silane groups, the thermogram becomes more complex because there are less decomposition steps. This could be because steric impediment stress chemical bonds forcing disintegration at a same time.

We expect that whether we use a lower concentration of polymer, we will have a lower thickness too. In figure 10 the thickness of product $\mathrm{P}_{111}$ are shown in the SEM images. the thickness of coatings of product $\mathrm{P}_{111}$ (in $\left.\mu \mathrm{m}\right)$ are observed. We verify that as polymer concentration is decreased the thickness also decrease. As we stated in figure 7, contact angle is reached to lower concentrations, it means that a higher contact angle will be reached whether we are closer to form a hydrophobic monolayer on the glass surface.
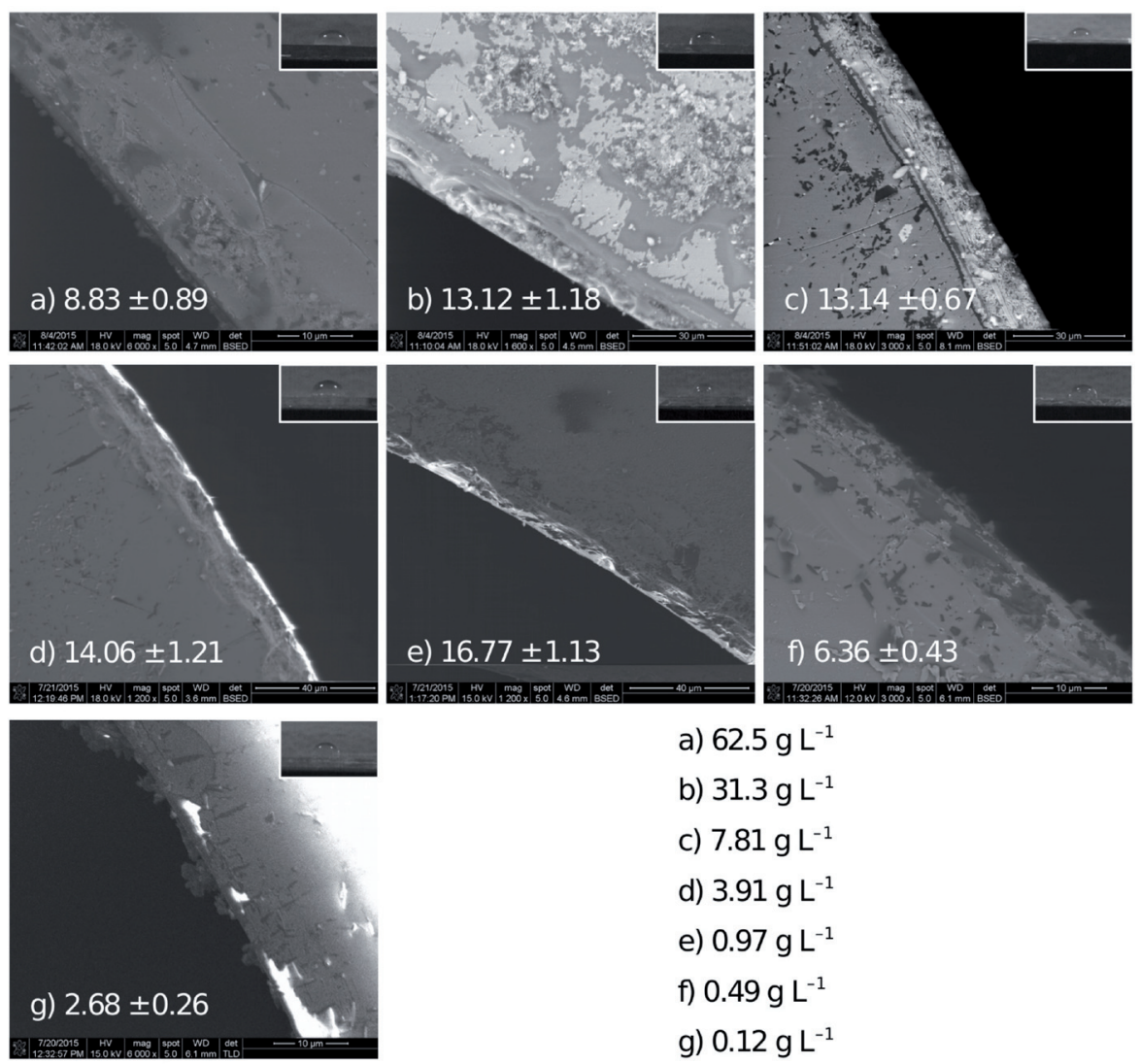
a) $62.5 \mathrm{~g} \mathrm{~L}^{-1}$
b) $31.3 \mathrm{~g} \mathrm{~L}^{-1}$
c) $7.81 \mathrm{~g} \mathrm{~L}^{-1}$
d) $3.91 \mathrm{~g} \mathrm{~L}^{-1}$
e) $0.97 \mathrm{~g} \mathrm{~L}^{-1}$
f) $0.49 \mathrm{~g} \mathrm{~L}^{-1}$
g) $0.12 \mathrm{~g} \mathrm{~L}^{-1}$

Fig. 10. Thickness of product $P_{111}$ at several polymer concentrations (values in $\mu \mathrm{m}$ ). 


\section{CONCLUSION}

The synthesis of carbamates derivatives was possible profiting reactivity of urethane bond, specially because it is a simple way to increase hydrophobicity parting from a same structure without the utilization of another reactants.

When silane number within the molecule is increased, hydrophobicity was improved due that the molecule has more groups which let be attached on the glass surface. Thus, molecule adopt a more rigid structure orientating hydrophobic fluorine outside. With the inclusion to the urethane bond of just one silane group is enough to improve hydrophobicity. However, when there are so many groups around the same bond, this results in a great steric impediment where silane groups locally compete for the same sites, resulting in a chaotic deposition. As reflected in their thermal temperature decomposition, we speculate that product structures should be similar.

\section{ACKNOWLEDGMENTS}

We acknowledge the financial support from CONACyT trough research Grant 133103 and The Universidad Autónoma de Nuevo León (CIIDIT).

\section{REFERENCES}

1. B.J. Basu, V. Hariprakash, S.T. Aruna, R. V Lakshmi, J. Manasa, B.S. Shruthi, Effect of microstructure and surface roughness on the wettability of superhydrophobic sol-gel nanocomposite coatings, J. Sol-Gel Sci. Technol. 56 (2010) 278-286.

2. M. Ma, R.M. Hill, Superhydrophobic surfaces, Curr. Opin. Colloid Interface Sci. 11 (2006) 193-202.

3. V.G. Parale, D.B. Mahadik, M.S. Kavale, S.A. Mahadik, A.V. Rao, S. Mullens, Sol-gel preparation of PTMS modified hydrophobic and transparent silica coatings, J. Porous Mater. 20 (2013) 733-739.

4. N. Valipour M., F.C. Birjandi, J. Salgolzaei, Super-non-wettable surfaces: A review, Colloids Surfaces A Physicochem. Eng. Asp. 448 (2014) 93-106.

5. M. Nosonovsky, B. Bhushan, Superhydrophobic surfaces and emerging applications: Non-adhesion, energy, green engineering, Curr. Opin. Colloid Interface Sci. 14 (2009) 270-280.

6. J.. Cras, C.. Rowe-Taitt, D.. Nivens, F.. Ligler, Comparison of chemical cleaning methods of glass in preparation for silanization, Biosens. Bioelectron. 14 (1999) 683-688.

7. P. Innocenzi, M.O. Abdirashid, M. Guglielmi, Structure and properties of sol-gel coatings from methyltriethoxysilane and tetraethoxysilane, J. Sol-Gel Sci. Technol. 3 (1994) 47-55.

8. G. Kumar, K.N. Prabhu, Review of non-reactive and reactive wetting of liquids on surfaces., Adv. Colloid Interface Sci. 133 (2007) 61-89.

9. V.V. Ganbavle, U.K.H. Bangi, S.S. Latthe, S.A. Mahadik, A.V. Rao, Selfcleaning silica coatings on glass by single step sol-gel route, Surf. Coatings Technol. 205 (2011) 5338-5344. 
10.J.W. Krumpfer, T.J. McCarthy, Rediscovering silicones: "unreactive" silicones react with inorganic surfaces., Langmuir. 27 (2011) 11514-9.

11.C.. van Oss, R.. Good, M.. Chaudhury, The role of van der Waals forces and hydrogen bonds in "hydrophobic interactions" between biopolymers and low energy surfaces, J. Colloid Interface Sci. 111 (1986) 378-390.

12.C.J. van Oss, Long-range and short-range mechanisms of hydrophobic attraction and hydrophilic repulsion in specific and aspecific interactions., J. Mol. Recognit. 16 (2003) 177-90. doi:10.1002/jmr.618.

13.D.G. Castner, D.W. Grainger, Fluorinated Surfaces, Coatings, and Films, Primera, American Chemical Society, Washington, DC, 2001.

14.M.G. Dhara, S. Benerjee, Fluorinated high-performance polymers: Poly(arylene ether)s and aromatic polyimides containing trifluoromethyl groups, Prog. Polym. Sci. 35 (2010) 1022-1077.

15.V.C. Malshe, N.S. Sangaj, Fluorinated acrylic copolymers: Part I: Study of clear coatings, Prog. Org. Coatings. 53 (2005) 207-211.

16.N. Kiraz, E. Burunkaya, Ö. Kesmez, M. Asiltürk, H. Erdem Çamurlu, E. Arpaç, Sol-gel synthesis of 3-(triethoxysilyl)propylsuccinicanhydride containing fluorinated silane for hydrophobic surface applications, J. Sol-Gel Sci. Technol. 56 (2010) 157-166.

17.E. Burunkaya, N. Kiraz, Ö. Kesmez, M. Asilturk, H. Erdem Çamurlu, E. Arpaç, Sol-gel synthesis of IPTES and D10H consisting fluorinated silane system for hydrophobic applications, J. Sol-Gel Sci. Technol. 56 (2010) 99-106.

18.J. Kozakiewicz, J. Przybylski, K. Sylwestrzak, I. Ofat, New family of functionalized crosslinkers for heat-curable polyurethane systems-A preliminary study, Prog. Org. Coatings. 72 (2011) 120-130.

19.Q.-W. Lu, T.R. Hoye, C.W. Macosko, Reactivity of Common Functional Groups with Urethanes: Models for Reactive Compatibilization of Thermoplastic Polyurethane Blends, J. Polym. Sci. Part A Polym. Chem. 40 (2002) 2310-2328.

20.K. Schwetlick, R. Noack, Kinetics and catalysis of consecutive isocyanates reactions. Formation of carbamates, allophanates and isocyanurates, J. Chem. Soc. Perkin Trans. 2. (1995) 395-402.

21.R. Blossey, Self-cleaning surfaces--virtual realities., Nat. Mater. 2 (2003) 301-6.

22.E. Delebecq, J.-P. Pascault, B. Boutevin, F. Ganachaud, On the Versatility of Urethane/Urea Bonds: Reversibility, Blocked Isocyanate, and Non-isocyanate Polyurethane, Chem. Rev. 113 (2013) 80-118.

23.F. Ferrero, M. Periolatto, Application of fluorinated compounds to cotton fabrics via sol-gel, Appl. Surf. Sci. 275 (2013) 201-207.

24.A.G. Kannan, N.R. Choudhury, N. Dutta, Fluoro-silsesquioxane-urethane hybrid for thin film applications., ACS Appl. Mater. Interfaces. 1 (2009) 336-47.

25.N. Stobie, B. Duffy, J. Colreavy, P. McHale, S.J. Hinder, D.E. McCormack, Dual-action hygienic coatings: Benefits of hydrophobicity and silver ion 
release for protection of environmental and clinical surfaces, J. Colloid Interface Sci. 345 (2010) 286-292.

26.M.M. Coleman, D.J. Skrovanek, J. Hu, P.C. Painter, Hydrogen bonding in polymer blends. 1. FTIR studies of urethane-ether blends, Macromolecules. 21 (1988) 59-65.

27.P. Dimitrakopoulos, Gravitational effects on the deformation of a droplet adhering to a horizontal solid surface in shear flow, Phys. Fluids. 19 (2007) 122105.

28.H. Hu, R.G. Larson, Evaporation of a Sessile Droplet on a Substrate, J. Phys. Chem. B. 106 (2002) 1334-1344.

29.E.L. Decker, B. Frank, Y. Suo, S. Garoff, Physics of contact angle measurement, Colloids Surfaces A Physicochem. Eng. Asp. 156 (1999) 177-189.

30.D.. Kwok, A.. Neumann, Contact angle interpretation in terms of solid surface tension, Colloids Surfaces A Physicochem. Eng. Asp. 161 (2000) 31-48.

31.M. Miwa, A. Nakajima, A. Fujishima, K. Hashimoto, T. Watanabe, Effects of the surface roughness on sliding angles of water droplets on superhydrophobic surfaces, Langmuir. 16 (2000) 5754-5760.

32.R. Tadmor, Line energy and the relation between advancing, receding, and young contact angles., Langmuir. 20 (2004) 7659-64.

33.S.-Y. Moon, J.-S. Bae, E. Jeon, J.-W. Park, Organic Sol-Gel Synthesis: Solution-Processable Microporous Organic Networks, Angew. Chemie. 122 (2010) 9694-9698.

34.A. Cunha, C.S.R. Freire, A.J.D. Silvestre, C.P. Neto, A. Gandini, E. Orblin, et al., Highly Hydrophobic Biopolymers Prepared by the Surface Pentafluorobenzoylation of Cellulose Substrates, Biomacromolecules. 8 (2007) 1347-1352.

35.H.-D. Hwang, H.-J. Kim, UV-curable low surface energy fluorinated polycarbonate-based polyurethane dispersion, J. Colloid Interface Sci. 362 (2011) 274-284.

36.M.A. Semsarzadeh, A.H. Navarchian, Effects of $\mathrm{NCO} / \mathrm{OH}$ ratio and catalyst concentration on structure, thermal stability, and crosslink density of poly(urethane-isocyanurate), J. Appl. Polym. Sci. 90 (2003) 963-972.

37.P.I. Kordomenos, J.E. Kresta, Thermal stability of isocyanate-based polymers. 1. Kinetics of the thermal dissociation of urethane, oxazolidone, and isocyanurate groups, Macromolecules. 14 (1981) 1434-1437.

38.X. Qiang, X. Ma, Z. Li, X. Hou, Synthesis of star-shaped polyhedral oligomeric silsesquioxane (POSS) fluorinated acrylates for hydrophobic honeycomb porous film application, Colloid Polym. Sci. 292 (2014) 1531-1544. 